\title{
The Diversity of Fishes: The Known and Unknown
}

W

hen first approached about the possibility of a census to assess and explain the diversity, distribution, and abundance of the world's marine life, I appreciated the value of such an effort for a variety of reasons, some personal and broader than the immediate issue of knowing more about the ocean's biology. A term as Assistant Secretary General for Scientific Affairs at NATO in 1960-1962 first exposed me to the modern problems in taxonomy. Interest in the environment was growing and being organized into a more effective and technically oriented endeavor and more accepted on the political and diplomatic plane.

My colleague, Brian Coleby, and I became aware of the contradictory fact that the interest and support of classical taxonomy was declining just when the burgeoning interest in the environment required an enhanced effort in understanding effects of human activities on the biosystems. This was and still is especially true in the United States. The NATO science program had funds, and working within our charter, we financed several meetings and work programs on the subject of chemical taxonomy that we hoped would reverse the declining interest. It may have slowed the rate of decline, but that was all.

My next opportunity came in the 1980 s as a member of the National Science Board (NSB), the governing body of the US National Science Foundation (NSF). Biodiversity had emerged as a major ecological concern. I proposed and became the first chair of an NSB committee on biodiversity and it helped stimulate the NSF to greater efforts in the field. It was not a total success because of a tendency to bypass the classical field in the hope that DNA analysis would be a more economical and certainly more comfortable way of getting the job done. This approach disappoints because up to the present few DNA practitioners are field biologists.

A clear example of the failure of the US community in biodiversity was the lagging effort on the classification of the flora of the North American continent. Despite many years of existence, the Flora of North America project remains far from complete. Of paramount importance for many reasons but certainly in ecological and environmental matters, it needs far greater support, probably federal. I did persuade Academic Press to create an Encyclopedia of Environmental Biology, a practical tool for codifying knowledge of both terrestrial and marine ecosystems, but obviously much greater effort is needed.

This history indicates why I was pleased to help the Sloan Foundation's studies of the value and feasibility of a Census of Marine Life. The vehicle was the first of many meetings to develop an active program that clearly had to be of considerable magnitude and would require the combined efforts of several kinds of agencies, public and private, around the world.

A logical beginning was the formation of a worldwide assemblage of ichthyologists for several days and the construction of their combined assessment of the state of knowledge of the oceans' fish species. Invitations were issued to all the major world centers of research and classification, and almost all were represented at the meeting, except Russia. In total, seventeen ichthyologists, plus several additional participants involved in ecology or technology, attended the meeting, held in March of 1997. Scripps Institution of Oceanography hosted the meeting, in view of its role in expeditions, the collections it holds, and the tradition of work by such scientists as Richard Rosenblatt, who played a major role in the organization and conduct of the meeting.

As can be inferred from an earlier remark, the number of expert taxonomists in the field is small and decreasing. An early point of consensus among participants was that the number of students is inadequate for that needed for sustained field research. US participants, however, introduced a note of optimism with a discussion of the Interagency Taxonomic Information System (ITIS), networking the Departments of Agriculture and Interior, National Oceanic and Atmospheric Administration, the Environmental Protection Agency, and Smithsonian Institution. They are coupled to international operations as well. This activity, it is hoped, may contribute to a reversal in the decline in taxonomy and systematics. 
The bottom line of the meeting was the result of a poll taken of the experts on their estimates of the number of known and unknown fish species. The current total of the known fishes is around 25,000 , of which $60 \%$ are saltwater (marine) and the remainder are freshwater. The combined estimate of the number of marine species yet to be identified is around 5,000, making a total number of marine species equal to around 20,000. I would summarize

... considering marine fish species alone,

the age of discovery is not over.
Explorations in this and other more difficult environments have depended heavily on opportunistic gifts of time on oceanographic vessels primarily funded for physical oceanographic or marine geological research. The major regions of the world's oceans that remain to be more thoroughly investigated for new species of fishes are the South Pacific, Western Indian Ocean, Western Equatorial Pacific, and Australasian Seas. Connecting observed diversity with theory is obviously a big scientific question.

This author, not an ichthyologist, is strongly impressed by the achievements of the small group of experts in ichthyology in sustaining the momentum of their research and classifications. They maintain their research in the face of declining support despite their small numbers, geographical dilution, and the pressure of other, if related, duties such as teaching, maintenance of collections, and operation of museums. The decline that would have occurred has been counterbalanced by the adaptation of developing technology. A worldwide program to census fishes or marine life could clearly give a valuable boost to a field that has been rather neglected and can discover much.

Dr

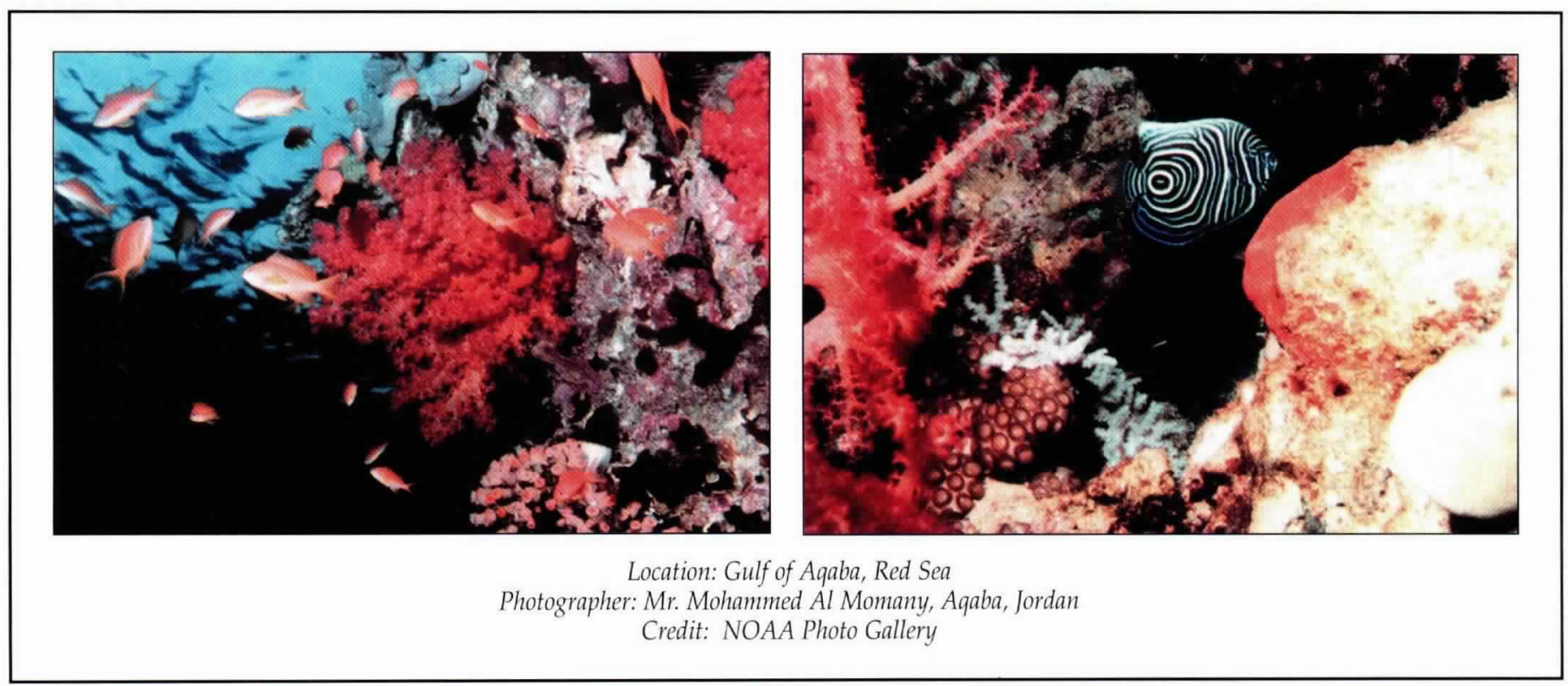

